\title{
Traces of memory: Reacquisition of fear following forgetting is NMDAr-independent
}

\author{
Stella $\mathrm{Li}^{1}$ and Rick Richardson \\ School of Psychology, The University of New South Wales, Sydney, New South Wales 2052, Australia
}

\begin{abstract}
Recent research shows that while initial learning is dependent on $\mathrm{N}$-methyl-D-aspartate receptors (NMDArs), relearning can be NMDAr-independent. In the present study we examined whether this switch also occurs following forgetting. The developing animal exhibits much more rapid rates of forgetting than adults, so infant rats were used. It was found that infant rats required NMDArs to learn fear (Experiment 1), and that this memory was forgotten after $14 \mathrm{~d}$ (Experiment 2). Despite forgetting, relearning fear did not require NMDAr activation (Experiment 3), even if it occurred in adulthood (Experiment 5). Importantly, animals only showed NMDAr-independent reacquisition if they had received paired (white noise-shock) training during conditioning and not if they received unpaired presentations of the white noise and shock (Experiment 4). In addition, this transition following forgetting was not stimulus specific as learning about a novel stimulus (i.e., light, Experiment 6) was also NMDAr-independent. However, reacquisition to a novel stimulus was NMDAr-dependent if the original fear memory was retained at the time of retraining (Experiment 7). Taken together, these results demonstrate how fear memories acquired early in life can have a long-lasting impact on later learning, even when they have been apparently forgotten (i.e., they are not expressed in the animal's overt behavior). Further, they support the idea that while memories may be forgotten, they are not gone.
\end{abstract}

In the laboratory, fear acquisition is most commonly studied through Pavlovian conditioning, where an initially neutral conditioned stimulus (CS, such as a white noise) is paired with an aversive unconditioned stimulus (US, such as a footshock). The animal quickly learns to fear the CS, such that future presentations of the CS elicit a range of defensive responses, such as freezing in the rat. In recent years, considerable progress has been made in our understanding of the neurobiology of fear learning. In contrast, we know considerably less about the neurobiology of forgetting and, in particular, the consequences of forgetting on subsequent learning. One reason why there has been less focus on forgetting is because adult animals have excellent retention, especially of learned fear where it has been shown that adult rats remember for up to 16 mo (Gale et al. 2004). In contrast, infant animals exhibit a very rapid rate of forgetting, a phenomenon known as infantile amnesia (Campbell and Campbell 1962; Campbell and Spear 1972; Kim et al. 2006). It is important to note that infantile amnesia is not due to an inability to acquire fear as infant and adult animals demonstrate equivalent levels of learning when tested shortly after training (e.g., Campbell and Campbell 1962).

It has been suggested that aversive experiences during childhood have lifelong consequences and may lead to the formation of adult psychopathologies (Sanchez et al. 2001). While this idea is seemingly at odds with the infantile amnesia literature, some recent studies have shown that apparently forgotten infant memories can leave a trace, even if they are no longer expressed in the animal's behavior. For instance, Kim et al. (2012) showed that, despite forgetting on a behavioral level, infant rats exhibited persisting neural activity in the amygdala that reflected early-life learning. In addition, Sevelinges and colleagues found that adverse early-life experiences can have an enduring effect on later learning (Sevelinges et al. 2007). In that study, infant rats that had received paired presentations of a peppermint odor CS and

\footnotetext{
1Corresponding author

E-mail ssli@psy.unsw.edu.au

Article is online at http://www.learnmem.org/cgi/doi/10.1101/Im.029504.112.
}

a shock US across postnatal day 8 (P8) to P12 showed attenuated freezing when they were retrained in adulthood using the same odor CS. In addition to those recent findings, a number of other studies, including many reported in the 1960s and 1970s, have shown that forgetting (i.e., failure to exhibit the learned response) can be attenuated if subjects, both infant rats and human infants, receive a reminder treatment prior to test (Campbell and Jaynes 1966; Spear and Parsons 1976; Davis and Rovee-Collier 1983; Kim et al. 2006). Taken together, these studies suggest that, despite the lack of behavioral expression of the original memory, some form of the memory trace must still exist. In the present study, we further explored how fear conditioning during infancy impacts later learning, even though that initial learning is not expressed behaviorally. Specifically, in this study we examined how forgotten fear memories affect the neurobiology of later learning.

As previously mentioned, the neurobiology underlying fear acquisition has been extensively investigated. That work has shown that the amygdala is fundamental to learning, storing, and expressing fear (Davis 1992; LeDoux 2000). On a molecular level, fear acquisition activates a complex intracellular cascade that involves the release of glutamate, the activation of protein kinases, and the synthesis of new proteins (Kandel 2001). Blocking or preventing a single step in the molecular cascade impairs memory formation. For instance, systemic and intra-amygdalar administration of $N$-methyl-D-aspartate receptor (NMDAr) antagonists such as MK-801 or 2-amino-5-phosphonovaleric acid (APV) have been shown to impair fear acquisition in adult, juvenile, and infant rats (Miserendino et al. 1990; Fanselow and Kim 1994; Rodrigues et al. 2001; Langton et al. 2007; Laurent and Westbrook 2009). NMDArs have also been shown to be important for other learning tasks such as spatial learning (Butelman 1989; Morris 1989), object recognition (de Lima et al. 2005), the social transmission of food preferences (Roberts and Shapiro 2002), and eyeblink conditioning (Takatsuki et al. 2001).

However, some studies have challenged the view that NMDArs are obligatory for learning. Indeed, there are several circumstances where learning can occur without the involvement of 
NMDAr-independent relearning following forgetting

NMDArs. One of these circumstances is when animals learn for the second time, which is usually referred to as "relearning" or "reacquisition." On a behavioral level, reacquisition of fear has been shown to be more rapid than initial acquisition, an effect known as "savings" (Bouton 1993). Additionally, while initial acquisition is NMDAr-dependent, several studies have shown that a previous learning experience, or mere prior exposure to the training context, can render future learning NMDAr-independent (Bannerman et al. 1995; Saucier and Cain 1995; Roesler et al. 1998, 2000; Sanders and Fanselow 2003; Tayler et al. 2011; Wiltgen et al. 2011; see also Lee and Kim 1998). For example, Sanders and Fanselow (2003) examined the effect of intrahippocampal infusion of APV on contextual fear conditioning. As expected, rats that were infused with APV prior to training showed impaired contextual fear conditioning. However, if rats were preexposed to a different context prior to training, then APV did not impair contextual fear conditioning. This suggests that a prior learning experience rendered future training NMDAr-independent. In other words, there is a switch from NMDAr-dependent learning to NMDAr-independent relearning.

It is of interest to note, however, that in all the previous studies examining this switch to NMDAr-independent relearning, the original memory had been retained and the animal could express it on a behavioral level at the time of relearning. In the present study we examined whether this switch still occurs despite the animal forgetting the original memory, that is, once animals are no longer expressing fear on a behavioral level. A previous study has examined this issue by experimentally inducing retrograde amnesia through an infusion of anisomycin following training (Hardt et al. 2009). Using the same experimental design as Sanders and Fanselow (2003), Hardt et al. (2009) showed that prior training eliminated the need for NMDArs during later conditioning, but if the pre-training memory was lost or abolished (due to posttraining anisomycin infusion) then future learning remained NMDAr-dependent.

In the present study we examined whether the transition from NMDAr-dependent learning to NMDAr-independent relearning still occurs despite the animal exhibiting spontaneous forgetting (i.e., infantile amnesia) of the original memory. In these experiments, P17 rats were trained with six white noiseshock pairings. Once these animals exhibited pronounced forgetting, they were retrained. We expected that the forgotten infant fear memory would still impact relearning; that is, the hypothesis was that relearning would not be mediated by NMDArs and therefore not be affected by administration of NMDAr-antagonists such as MK-801. If this hypothesis was incorrect and the forgetting process involved the decay of the original memory trace, especially at longer retention intervals, then relearning later in life would be similar to initial acquisition and thereby rely on NMDAr activity.

\section{Results}

\section{Experiment 1: Acquisition of fear is NMDAr-dependent in $\mathrm{P} 17$ rats}

Before examining whether NMDArs are involved in reacquisition of fear, we first investigated whether they play a role in fear acquisition in P17 (infant) rats. Ten minutes prior to conditioning, P17 rats were injected with MK-801, an NMDAr-antagonist, or saline. Conditioning consisted of six white noise-shock pairings. All rats were then tested, drug-free, the next day for their baseline and CS-elicited freezing levels. At test, there were no differences in pre-CS levels of freezing, $F_{(1,16)}=3.88, P=0.066$ (baseline levels of freezing for all experiments can be found in Table 1 ). There were, however, significant differences in CS-elicited freezing, where animals injected with MK-801 exhibited less freezing than animals
Table 1. Baseline ( \pm SEM) levels of freezing at test in all experiments

\begin{tabular}{|c|c|c|c|}
\hline Experiment & & Group & \\
\hline 1 & $\begin{array}{l}\text { MK-801 } \\
16(6.3)\end{array}$ & $\begin{array}{l}\text { Saline } \\
2.5(1.4)\end{array}$ & \\
\hline 2 & $\begin{array}{l}1 \mathrm{~d} \\
11.3(4.8)\end{array}$ & $\begin{array}{l}7 \mathrm{~d} \\
3.1(2.7)\end{array}$ & $\begin{array}{l}14 \mathrm{~d} \\
\quad 3.9(0.7)\end{array}$ \\
\hline 3 & $\begin{array}{c}\text { Paired-MK } \\
10.4(4.1) \\
\text { Paired-saline } \\
11.7(3.3)\end{array}$ & $\begin{array}{l}\text { Exposure-MK } \\
0(0) \\
\text { Exposure-saline } \\
10(4.6)\end{array}$ & \\
\hline 4 & $\begin{array}{c}\text { Paired-MK } \\
9.6(4.5) \\
\text { Paired-saline } \\
10.8(3.5)\end{array}$ & $\begin{array}{c}\text { Unpaired-MK } \\
3.8(2.2) \\
\text { Unpaired-saline } \\
18.9(5.5)\end{array}$ & \\
\hline 5 & $\begin{array}{c}\text { Paired-MK } \\
2(1.2) \\
\text { Paired-saline } \\
11(4.7)\end{array}$ & $\begin{array}{l}\text { Exposure-MK } \\
0(0) \\
\text { Exposure-saline } \\
4.4(4.7)\end{array}$ & \\
\hline 6 & $\begin{array}{c}\text { Same-MK } \\
14(7.8) \\
\text { Same-saline } \\
10.7(3.6)\end{array}$ & $\begin{array}{l}\text { Novel-MK } \\
5.5(2.5) \\
\text { Novel-saline } \\
9.4(7)\end{array}$ & \\
\hline 7 & $\begin{array}{l}\text { P17-MK } \\
7.1 \text { (3.1) } \\
\text { P17-saline } \\
3.1(2.7)\end{array}$ & $\begin{array}{l}\text { P30-MK } \\
6.5(2.9) \\
\text { P30-saline } \\
6.9(3.2)\end{array}$ & \\
\hline
\end{tabular}

injected with saline, $F_{(1,16)}=9.15, P=0.008$ (Fig. 1 ). This finding replicates a previous demonstration that NMDArs are involved in infant fear learning (Langton et al. 2007).

\section{Experiment 2: Retention of fear in P17 rats}

Experiment 2 examined how long infant rats, trained with the present parameters, retain learned fear. Unlike adult rats that retain fear memories for almost their entire lifespan (Gale et al. 2004), infant rats typically exhibit rapid forgetting (Campbell and Campbell 1962; Campbell and Spear 1972; Kim et al. 2012). This infantile forgetting provides an effective way of examining the neurobiology underlying forgetting and reacquisition. P17 rats were trained as in Experiment 1 and then tested 1, 7, or $14 \mathrm{~d}$ later. A one-way ANOVA showed there was no difference in baseline levels of freezing across the three groups, $F_{(2,20)}=$ $3.109, P=0.067$. There was, however, a significant group difference in terms of CS-elicited freezing, $F_{(2,20)}=10.72, P=0.001$. Post-hoc comparisons, using the Student-Newman-Keuls (SNK) test, showed that after $7 \mathrm{~d}$ rats exhibited significantly less freezing than after $1 \mathrm{~d}, P<0.05$ (Fig. 2). After $14 \mathrm{~d}$ rats were freezing at negligible levels and exhibited less fear than rats tested after 1 or $7 \mathrm{~d}$, $P^{\prime} \mathrm{s}<0.05$. Thus, using the present parameters infant rats exhibited complete forgetting $14 \mathrm{~d}$ after training.

\section{Experiment 3: Reacquisition of fear is NMDAr-independent following forgetting}

Previous studies have shown that while initial learning is mediated by NMDArs, in some circumstances relearning fear is NMDAr-independent (e.g., Sanders and Fanselow 2003; Wiltgen et al. 2011). In Experiment 3, we tested whether relearning to fear a stimulus that no longer elicits any behavioral fear requires the activation of NMDArs. P17 rats were either trained with six white noise-shock pairings or exposed to the conditioning context for the same amount of time. After $2 \mathrm{wk}$, these rats (now $31 \mathrm{~d}$ of age) were injected with either MK-801 or saline. Ten minutes later, they were given three white noise-shock pairings. All rats were tested, drug-free, the next day. 


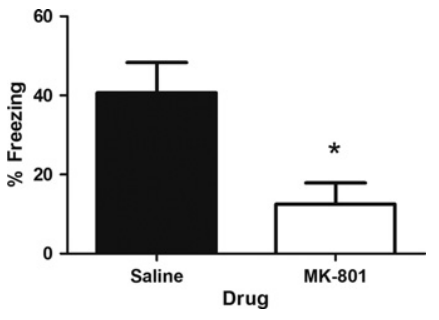

Figure 1. Mean $( \pm$ SEM) CS-elicited freezing at test in P17 rats given either MK-801 $(n=10)$ or saline $(n=8)$ prior to fear conditioning. $\left(^{*}\right)$ Significant difference $(P<0.05)$ from the saline group.

During reacquisition, rats in the paired and exposure groups (collapsed across drug) exhibited 3\% and 0\% freezing, respectively, during the first white noise CS presentation; this difference in freezing was not significant, $F_{(1,48)}=2.08, P=0.16$, and shows that the trained rats exhibited complete forgetting. At test, there were no differences in pre-CS levels of freezing (i.e., there were no main effects or interaction, largest $F_{(1,46)}=3.07, P=0.086$ ). There were differences in CS-elicited fear, however, with all groups except the exposure-MK group showing high levels of freezing at test (Fig. 3). A 2 (drug: MK or saline) $\times 2$ (condition: exposure or paired at P17) ANOVA confirmed this description of the results with the main effect of drug, $F_{(1,46)}=14.53, P<0.001$, condition, $F_{(1,46)}=23.39, P<0.001$, and drug $\times$ condition interaction, $F_{(1,46)}=6.1, P=0.017$, all being significant. SNK post-hoc tests revealed that the exposure-MK group differed significantly from all other groups, $P$ 's $<0.05$. There were no other group differences, smallest $P=0.23$. Therefore, rats previously trained to fear the white noise CS as infants (i.e., at P17) did not require NMDAr activation to relearn their fear of this CS at P31, even though their performance on the first training trial showed that they had completely forgotten their infant experience with the CS. Although the switch from NMDAr-dependent learning to NMDAr-independent relearning has been shown in spatial tasks (Bannerman et al. 1995; Saucier and Cain 1995) and contextual fear conditioning (Sanders and Fanselow 2003; Hardt et al. 2009; Wiltgen et al. 2011), for the first time this experiment demonstrates that this switch also occurs in cued fear conditioning and, interestingly, even following the forgetting of the fear memory.

\section{Experiment 4: Initial learning, and not an aversive experience or familiarity with the CS, renders reacquisition NMDAr-independent following forgetting}

Experiment 3 showed that reacquisition following forgetting was NMDAr-independent. In the next experiment, we examined whether the nature of the early-life experience influences the neurobiology underlying reacquisition; that is, does learning have to occur at P17 or can the experience of the shock and white noise, in an unpaired manner, also make reacquisition NMDAr-independent? This question was of particular interest given that prior exposure to the CS and US alone has been shown to influence the switch to NMDAr-independent relearning in an inhibitory avoidance task and in extinction (Roesler et al. 1998; Chan and McNally 2009).

In this experiment, we gave P17 rats either paired or explicitly unpaired presentations of the CS and US (six of each). On P31, rats were administered either MK-801 or saline and then retrained to fear the white noise CS (three pairings given to all groups). During reacquisition, rats in both the paired and exposure groups (collapsed across drug) exhibited 0\% freezing during the first CS presentation, again replicating the total forgetting in the previ- ously trained animals. The next day all rats were tested, drug-free. At test, there were no differences in pre-CS levels of freezing (i.e., there were no main effects or interaction; largest $F_{(1,48)}=3.15, P=$ $0.17)$. Regardless of whether MK-801 or saline had been injected prior to reacquisition, animals that had received paired training at P17 showed high levels of CS-elicited freezing at test (Fig. 4). This replicates the findings from Experiment 3. In contrast, the unpaired-saline animals showed high levels of freezing compared to the unpaired-MK group. A 2 (drug: MK or saline) $\times 2$ (condition: paired or unpaired at P17) ANOVA confirmed this description of the results. The main effect of drug, $F_{(1,48)}=1.8, P=0.19$, was not significant. However, there was a main effect of condition, $F_{(1,48)}=4.31, P=0.043$, and a significant drug $\times$ condition interaction, $F_{(1,48)}=5.43, P=0.024$. Post-hoc SNK tests revealed that the unpaired-MK group was significantly different from all other groups, $P^{\prime} \mathrm{s}<0.05$. There were no other group differences, smallest $P=0.77$. Thus, the results of this experiment show that earlylife learning about a discrete CS explicitly influences the neurobiology underlying reacquisition of fear to that CS later in life and not merely the experience of aversive stimuli (US) or familiarity with the CS (see Chan and McNally 2009).

\section{Experiment 5: Reacquisition of fear is NMDAr-independent following forgetting even if relearning occurs in adulthood}

The findings from the previous two experiments demonstrate that reacquisition of fear was NMDAr-independent even if the original fear memory was no longer being behaviorally expressed. However, in those previous experiments, rats were retrained during adolescence, and therefore it is unclear whether the switch to NMDAr-independent relearning only occurs during this specific developmental period. Further, the retention interval used in the previous experiments was relatively short (14 d), and so relearning may be NMDAr-dependent after a longer interval. There are two reasons why the switch to NMDAr-independent relearning may not occur after a long retention interval. First, it may be that the memory trace has decayed to such a point that relearning is akin to initial acquisition (i.e., NMDAr-dependent). Second, it may be that a change in the temporal context, achieved through a long interval between acquisition and reacquisition, may prevent the switch to NMDAr-independent relearning, as has been found with re-extinction (Langton and Richardson 2010). To test this, in the present experiment the retention interval was increased from $14 \mathrm{~d}$ to $49 \mathrm{~d}$ and, as a result, animals were in adulthood at the time of retraining (approximately P65).

Animals were trained on P17 and received either six white noise-shock pairings or were merely exposed to the context. Once animals had reached adulthood (P65), they were retrained with three white noise-shock pairings. Ten minutes prior to training, rats were injected with either MK-801 or saline. During

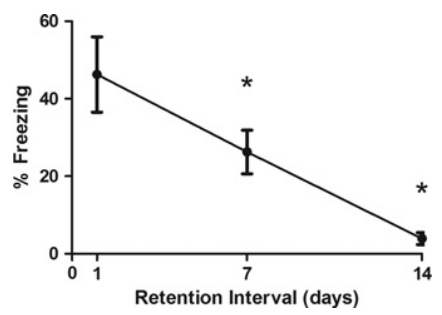

Figure 2. Mean ( \pm SEM) CS-elicited freezing at test in rats trained at P17 with six white noise-shock pairings. Rats were tested $1 \mathrm{~d}(n=8)$, $7 \mathrm{~d}(n=8)$, or $14 \mathrm{~d}(n=7)$ after training. (*) Significant difference $(P<$ 0.05 ) from other groups. 


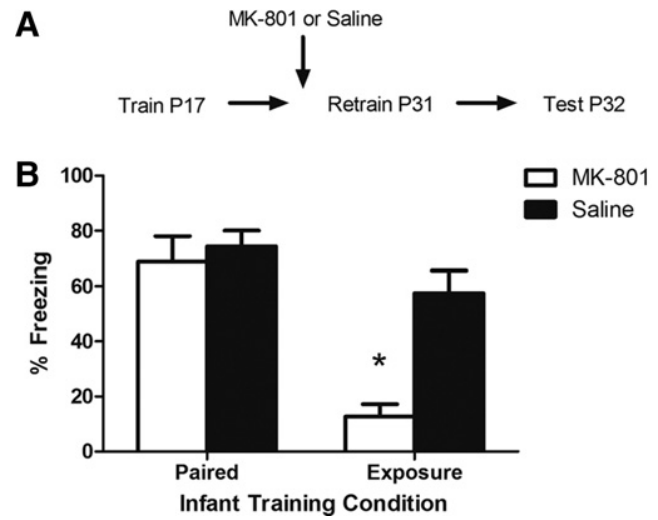

Figure 3. (A) The training protocol for Experiment 3. (B) Mean ( \pm SEM) CS-elicited freezing at test in rats given either MK-801 or saline prior to reacquisition. Rats that received previous training (paired groups) were unaffected by NMDAr-antagonism at reacquisition at P31 compared to animals that were merely exposed to the context (exposure groups) (ns $=12-13) .\left(^{*}\right)$ Significant difference $(P<0.05)$ from all other groups.

reacquisition, rats in the paired and exposure groups (collapsed across drug) exhibited $6.3 \%$ and $2 \%$ freezing, respectively, during the first white noise CS presentation; this difference was not significantly different, $F_{(1,36)}=1.89, P=0.18$. All rats were tested the next day, drug-free. At test, there were baseline differences in levels of freezing, with animals given MK-801 prior to reacquisition exhibiting less freezing than animals given saline (i.e., there was a main effect of drug, $F_{(1,34)}=4.82, P=0.035$, but no significant main effect of condition or interaction, $\left.P^{\prime} s \geq 0.17\right)$. Due to this difference, a 2 (drug: MK or saline) $\times 2$ (condition: paired or exposure at P17) ANCOVA, with baseline as a covariate, was conducted. There were main effects of drug, $F_{(1,33)}=18.92, P<0.001$, and condition, $F_{(1,33)}=12.46, P=0.001$, as well as a drug $\times$ condition interaction, $F_{(1,33)}=5.52, P=0.025$, for CS-elicited levels of freezing. Post-hoc SNK tests revealed that the exposure-MK group had significantly lower levels of freezing compared to the other three groups, $P^{\prime}$ s $<0.05$ (Fig. 5). There were no other group differences, smallest $P=0.08$. These results show that a memory acquired early in life, but that is no longer being behaviorally expressed, has an impact on learning in adulthood. Thus, the transition from NMDAr-dependent learning to NMDAr-independent relearning is not restricted to a specific developmental period (i.e., adolescence) or prevented by a longer retention interval. Although a previous study found that a change in temporal context was sufficient to prevent the switch to NMDAr-independent relearning in the case of extinction (Langton and Richardson 2010), this did not occur in the present experiment. That is, rats showed NMDAr-independent relearning even after $7 \mathrm{wk}$.

\section{Experiment 6: The transition to NMDAr-independent reacquisition following forgetting is not stimulus specific} The experiments in this study so far have demonstrated that the switch from NMDAr-dependent learning to NMDAr-independent relearning occurs following forgetting. Importantly, this transition only occurs if rats were given paired CS-US presentations at P17 and not if they were merely exposed to the context, CS, or US. One interesting question that follows from this is whether the switch to NMDAr-independent retraining occurs for any stimulus or whether the same CS used at initial conditioning needs to be used at retraining. In other words, is the transition to NMDAr-independent reacquisition following forgetting stimulus specific?
Animals were trained at P17 with the white noise CS (as described in Experiments 1-5). Two weeks later, rats were injected with either MK-801 or saline and $10 \mathrm{~min}$ later underwent reacquisition. At reacquisition, some rats were trained with the same CS used in original conditioning (white noise) while others were trained with a novel CS (light). During reacquisition, rats in the same and different CS groups (collapsed across drug) exhibited $6.6 \%$ and $3.3 \%$ freezing, respectively, during the first CS presentation; this difference was not significantly different, $F<1.0$. The next day, all groups were tested, drug free, for their fear of the CS used at reacquisition, either the white noise or the light. At test, there were no differences in either baseline or CS-elicited freezing (i.e., there were no significant main effects or interactions, largest $\left.F_{(1,27)}=3.53, P=0.07\right)$, with all groups showing high levels of fear to the CS (Fig. 6). In other words, administration of MK-801 prior to retraining had no effect on learning regardless of whether the rats were being retrained with the same CS as was used at P17 or with a novel CS. While the results with those rats retrained with the same CS replicate those of the previous experiments in this study, it was surprising that an injection of MK-801 prior to training at P31 did not impair learning about the novel light CS. This effect cannot be attributed to the drug failing to impair learning in P31 rats, as rats in the exposure-MK group from Experiment 3 showed NMDAr-dependent fear acquisition. In addition, the present results cannot be due to the light CS failing to be a salient stimulus, as similar levels of freezing were observed for both the light and the noise CSs. Thus, this experiment suggests that the previous learning at P17 renders learning about any discrete CS NMDAr-independent, regardless of whether the stimulus is familiar or novel.

\section{Experiment 7: Involvement of NMDArs in learning about a novel CS when memory for the original CS is intact}

The results from Experiment 6 showed that, following forgetting, it did not matter whether the same or a novel CS was used, as reacquisition of fear was NMDAr-independent in both cases. There are two possible explanations for this finding. First, it may be that, following conditioning, rats exhibit NMDAr-independent learning for all future learning experiences. Although this possibility is unlikely, it cannot be ruled out based on the results of
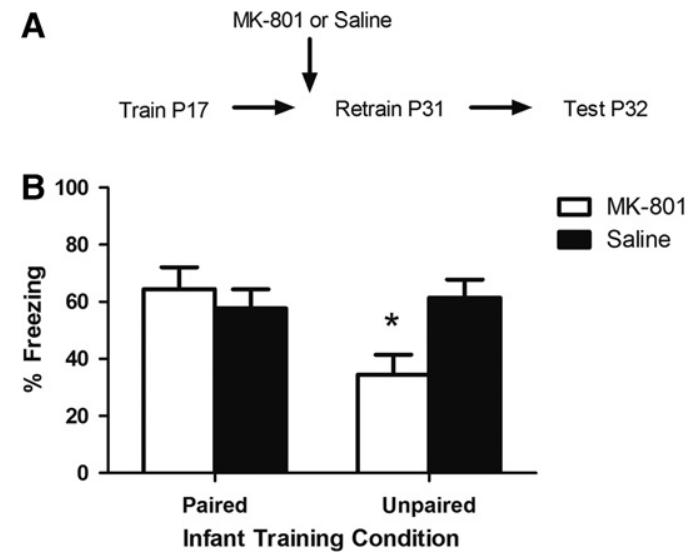

Figure 4. (A) The training protocol for Experiment 4. (B) Mean ( \pm SEM) CS-elicited freezing at test in rats given either MK-801 or saline prior to reacquisition. Reacquisition of fear at P31 following forgetting is NMDAr-independent only if rats received paired training at P17. Rats in the unpaired-MK group showed significantly lower levels of freezing compared to all other groups (ns $=13)$. $\left(^{*}\right)$ Significant difference $(P<$ 0.05) from all other groups. 
A

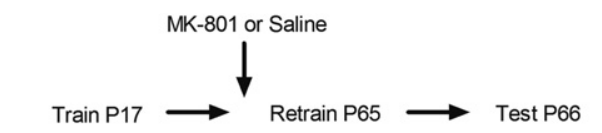

B

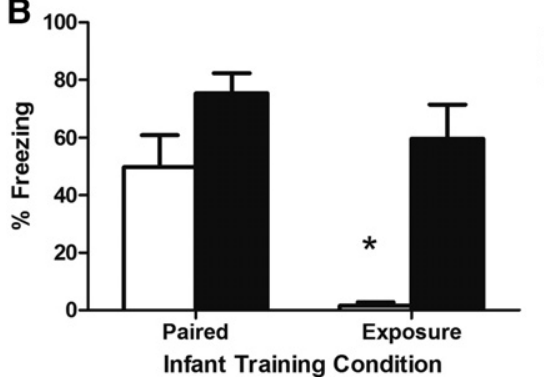

Figure 5. (A) The training protocol for Experiment 5. (B) Mean ( \pm SEM) CS-elicited freezing at test in rats given either MK-801 or saline prior to reacquisition. Reacquisition following forgetting is NMDAr-independent even if relearning occurs during adulthood $(\mathrm{ns}=8-10)$. (*) Significant difference $(P<0.05)$ from all other groups.

the previous experiment. Second, it may be that the process of forgetting results in a more general memory where the details are lost (Anderson and Riccio 2005). This is more likely to be observed for infant memories because young animals are more susceptible to rapid forgetting. One way to test both of these possibilities is to retrain animals when the original white noiseshock memory has not been forgotten. If rats continue to exhibit NMDAr-independent relearning to the novel CS, then this would provide support for the notion that the transition occurs for learning about any CS in the future. Alternatively, if rats exhibit NMDAr-dependent relearning to the novel CS in this case, then this would suggest that the results of Experiment 6 might have been due to the original memory becoming more general as it is forgotten.

In this experiment, P17 and P30 rats were trained, retrained, and tested over three consecutive days. On day 1, P17 and P30 rats were trained with either six or three white noise-shock pairings, respectively. The next day, animals were injected with either MK-801 or saline and $10 \mathrm{~min}$ later received three light-shock presentations. During reacquisition, P17 and P30 rats exhibited less than $12.4 \%$ and $19.9 \%$ freezing, respectively, during the first light CS presentation; the two age groups did not differ on this measure, $F<1.0$. The slightly higher levels of freezing observed in this experiment compared to previous experiments is most likely due to some residual effects of fear conditioning from the previous day. On day 3, all animals were tested, drug free, for their fear of the light CS. At test, there were no differences in pre-CS levels of fear (i.e., there were no significant main effects or interactions, all $\left.F^{\prime} \mathrm{s}<1.0\right)$. Rats of both ages injected with MK-801 exhibited less fear of the light CS than did saline-treated animals (Fig. 7). A 2 (drug: MK or saline) $\times 2$ (age: P17 or P30) ANOVA confirmed these results and revealed main effects of drug, $F_{(1,29)}=$ 30.6, $P<0.001$, and age, $F_{(1,29)}=8.84, P=0.006$, but no drug $\times$ age interaction, $F<1.0$. The main effect of age was driven by the slightly higher levels of freezing observed overall in the older animals and the main effect of drug was due to the lower levels of freezing in those rats injected with MK-801 prior to the training of the light CS. These results demonstrate that at both ages learning about the light CS was impaired by MK-801. In other words, prior fear conditioning does not render all future learning experiences to be NMDAr-independent. Rather, if the original fear memory is retained, then learning to fear a novel CS is NMDArdependent. It is only when the original memory is forgotten that learning to fear a novel CS becomes NMDAr-independent.

\section{Discussion}

In recent years, there has been an increasing interest in how memories acquired early in life contribute to learning later in life (e.g., Sevelinges et al. 2007). The present study extended this research by examining how even forgotten infant fear memories that are no longer expressed on a behavioral level still impact the neurobiology of later learning. Specifically, the switch from NMDArdependent learning to NMDAr-independent relearning was used to assess the presence of the original memory (Sanders and Fanselow 2003; Hardt et al. 2009; Archobold et al. 2010; Graham and Richardson 2011; Wiltgen et al. 2011). The results revealed that reacquisition of fear following forgetting was NMDAr-independent regardless of whether relearning occurred $14 \mathrm{~d}$ after training in adolescence (Experiments 3, 4, and 6) or $49 \mathrm{~d}$ later in adulthood (Experiment 5). This shows that there is at least a partial memory trace that exists even when the memory is no longer behaviorally expressed, and supports the idea that although memories are forgotten, they are not gone.

The notion that memories from infancy persist, despite clear evidence of forgetting on a behavioral level, is consistent with other findings in the literature. For instance, many studies have shown that a forgotten memory can be reactivated using either a pre-test reminder treatment (Campbell and Jaynes 1966; Spear and Parsons 1976; Davis and Rovee-Collier 1983) or administration of a pharmacological agent like epinephrine or FG-7142 (Haroutunian and Riccio 1977; Kim et al. 2006; Tang et al. 2007). In addition, recent work has also demonstrated that persisting activity in the amygdala may be a marker of past conditioning history (Kim et al. 2012). In that study, rats were trained on P16 with two white noise-shock pairings and tested $2 \mathrm{~d}$ later once forgetting had occurred. Despite failing to behaviorally express the memory, these animals showed heightened amygdalar activity as measured through pMAPK immunoreactivity. Given that Kim et al. (2012) used a shorter retention interval than that used in the present study, it would be of interest to examine how long this neural marker persists. Based on the results of Experiment 5, where rats that were trained on P17 showed NMDAr-independent relearning during adulthood, we would predict that heightened amygdalar activity would still be observed at least into adulthood.

In addition to demonstrating the transition from NMDArdependent learning to NMDAr-independent relearning following

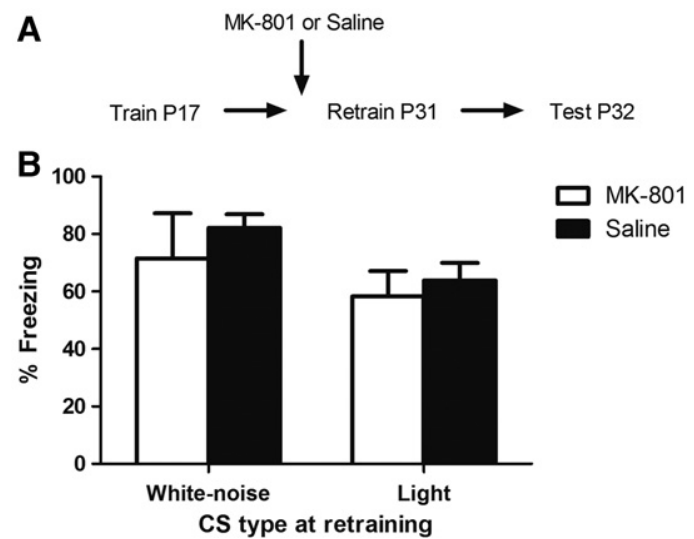

Figure 6. ( $A$ ) The training protocol for Experiment 6. (B) Mean ( \pm SEM) CS-elicited freezing at test in rats given either MK-801 or saline prior to reacquisition. The transition to NMDAr-independent reacquisition following forgetting is not stimulus specific. In other words, regardless of whether the same (white noise; $n s=5-7$ ) or a novel (light; $n s=9-10$ ) CS was used at reacquisition, animals in all groups exhibited high levels of fear. 
A
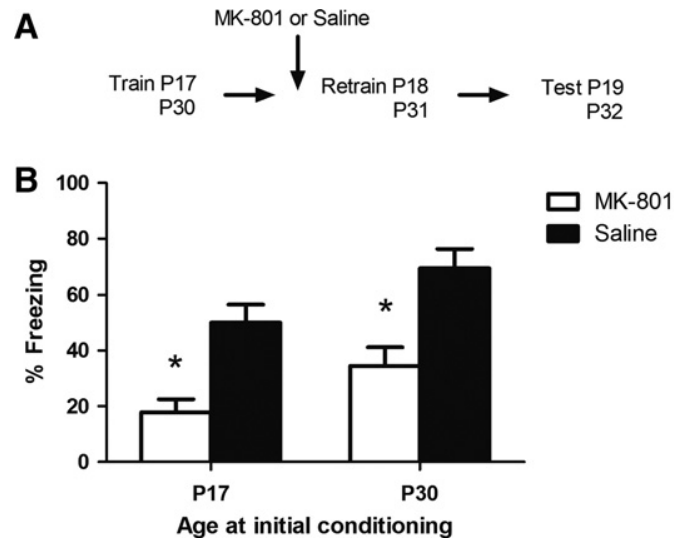

Figure 7. (A) The training protocol for Experiment 7. (B) Mean ( \pm SEM) CS-elicited freezing at test in rats given either MK-801 or saline prior to reacquisition. Animals were trained on P17 or P30 (white noise-shock), retrained on P18 or P31 (light-shock), and tested on P19 or P32 for their fear of the light CS (ns=7-10). $\left(^{*}\right)$ Significant difference $(P<$ 0.05 ) from the same-age saline group.

forgetting, the experiments reported in this paper also explored the conditions under which this switch occurs. Specifically, it was found that the switch to NMDAr-independent relearning was influenced by the nature of the initial training experience (see Sevelinges et al. 2007, 2008), but not by an increase in retention interval (but see Langton and Richardson 2010). However, the most surprising finding was that the switch to NMDAr-independent relearning following forgetting was not stimulus specific. That is, the results from Experiment 6 showed that following forgetting, reacquisition was NMDAr-independent regardless of whether the original or a novel CS was used. This finding was unexpected given that previous studies have shown that the effects of prior conditioning on later learning are stimulus specific (e.g., Sevelinges et al. 2007). Further, past research with discrete CSs has shown that the transition from NMDAr-dependent learning to NMDAr-independent relearning is also stimulus specific (Lee and Kim 1998; Langton and Richardson 2008). For instance, Lee and Kim (1998) found that despite prior training to a light CS, subsequent training to a tone CS remained NMDAr-dependent (it should be noted that such stimulus specificity is not observed for contexts, as Wiltgen et al. 2011 [among others] demonstrated that prior conditioning in Context A resulted in a transition to NMDAr-independent learning in Context B). Importantly, in the present study, reacquisition of fear was stimulus specific if training, retraining, and test occurred over consecutive days (Experiment 7). In other words, both infant P17 and adolescent P30 rats showed NMDAr-dependent learning to the novel light CS when the original white noise fear memory was not forgotten. It is possible that the forgetting process altered the nature of the memory, where the loss of details of the white noise CS ultimately caused the memory of the original training experience to become more generalized.

While these experiments demonstrated that relearning fear following forgetting is NMDAr-independent, it is unclear what mechanisms subserve learning following forgetting. Recent studies suggest that one of these mechanisms could be the activation of the calcium-permeable AMPA receptors (CP-AMPArs), which may have a role in mediating plasticity in the absence of NMDAr activation (Clem and Barth 2006; Clem et al. 2008; Wiltgen et al. 2010). For example, Wiltgen et al. (2010) demonstrated that CP-AMPArs mediated relearning of contextual fear in adult mice. In their study, mice were trained to fear Context A and the next day conditioned in Context B. Typically, studies have demonstrated that prior conditioning in Context A renders later learning in Context B NMDAr-independent (e.g., Sanders and Fanselow 2003; Hardt et al. 2009). However, prior to training in Context B, mice in that study were injected with saline, CPP (an NMDAr-antagonist), or CPP + IEM-1460 (an NMDAr and CPAMPAr-antagonist cocktail). Wiltgen et al. (2010) found that only mice that received CPP + IEM-1460 exhibited impaired learning to Context $\mathrm{B}$, suggesting that relearning contextual fear is CP-AMPAr-dependent. The role of CP-AMPArs in relearning is now only starting to be investigated, and at present nothing is known about the role of these receptors in relearning following forgetting. Therefore, it will be interesting to examine how CP-AMPArs regulate plasticity in situations where the memory was once expressed, but is now lost.

The results reported in the present study support previous research showing that the neurobiology underlying acquisition and reacquisition of fear relies on different processes, namely, that there is a transition from NMDAr-dependent learning to NMDAr-independent relearning (Roesler et al. 1998; Sanders and Fanselow 2003; Hardt et al. 2009). However, it should be noted that some studies have failed to find such a transition. In a study by Laurent and Westbrook (2009) rats were trained to fear Context A. Prior to conditioning, rats were either briefly or massively exposed to the training context. Regardless of the amount of exposure, Laurent and Westbrook (2009) found that the NMDAr-antagonist APV impaired contextual fear conditioning. In another study, Roesler et al. (2000) found that infusion of APV into the BLA blocked inhibitory avoidance learning in both naive rats and those who had been given previous training. Therefore, these latter studies suggest that NMDArs are obligatory for learning regardless of whether animals have been pre-exposed to the stimuli or have received prior training. The present series of experiments differs to those studies in several ways. For example, different NMDAr-antagonists, learning tasks, and ages of rats were used. However, it is unlikely that these differences alone can account for why the transition to NMDAr-independent relearning was not observed in those studies. Instead, the most notable distinction between the studies that do not show this transition (Lee and Kim 1998; Roesler et al. 2000; Laurent and Westbrook 2009) and the studies that do show this transition (Roesler et al. 1998; Sanders and Fanselow 2003; Hardt et al. 2009) is that the NMDAr-antagonist APV was infused into different brain structures prior to relearning. Specifically, the studies that observed the transition to NMDAr-independent relearning infused APV into the dorsal hippocampus, while studies that did not observe this transition infused APV into the BLA. Therefore, it may be that NMDArs in the amygdala are required for learning every single time, while hippocampal NMDArs are not. It should be noted, though, that APV has been shown to disrupt basal synaptic transmission in the BLA (Maren and Fanselow 1995; Bauer et al. 2002). Therefore, the observed impairments in reacquisition following intra-BLA infusions of APV could have been due to a disruption in neuronal activity, rather than specific blockade of the NMDArs. Future experiments should examine the role of NMDArs in relearning fear following forgetting through intraBLA infusions of ifenprodil, a selective antagonist of the NR2B subunit which, unlike APV, does not disrupt neuronal activity (Bauer et al. 2002).

Taken together, the experiments reported in the present study demonstrated the long-lasting impact of early-life fear learning by examining its consequences on the neurobiology of later relearning. While the impact of neonatal experiences on later learning and memory are well-established, most studies on this issue focus on the effects of chronic aversive experiences (e.g., earlylife stress). The experiments reported in this study showed that even a single aversive learning experience during infancy can 
have profound effects on adolescent and adult learning. That is, for the first time, it was demonstrated that there is a transition from NMDAr-dependent learning in infancy to NMDAr-independent relearning in adolescence or adulthood. Most importantly, these effects on later learning occur despite the forgetting of the infant fear memory. Thus, these results suggest that our current learning and memory processes, as adults, may be influenced by what we learned and experienced as children.

\section{Materials and Methods}

\section{Subjects}

Animals were experimentally naive Sprague-Dawley rats that were bred and housed in the School of Psychology, The University of New South Wales. All rats were male, and no more than one rat per litter was used per group. Rats were housed with their littermates and mother in plastic boxes $(24-\mathrm{cm}$ long $\times 27-\mathrm{cm}$ wide $\times$ $27-\mathrm{cm}$ high) covered by a wire lid throughout all experiments, except in Experiment 5. Animals in that experiment were housed with their littermates and mother until approximately P25, when they were weaned and placed in plastic boxes $(67-\mathrm{cm}$ long $\times 40-\mathrm{cm}$ wide $\times 22-\mathrm{cm}$ high) in groups of eight. All animals were maintained on a 12-h light/dark cycle (lights on at 07.00) with food and water available ad libitum, and were treated according to the principles of animal use outlined in The Australian Code of Practice for the Care and Use of Animals for Scientific Purposes (National Health and Medical Research Council 2004). All procedures were approved by the Animal Care and Ethics Committee at The University of New South Wales.

\section{Apparatus}

All experiments were conducted in two distinct contexts. Initial conditioning and reacquisition occurred in the first type of chamber, while test was conducted in the second type. Both types of chambers were housed in separate sound- and light-attenuating cabinets.

\section{Conditioning}

In all experiments, fear conditioning of P17 rats occurred in a set of two identical rectangular chambers $(13.5-\mathrm{cm}$ long $\times 9-\mathrm{cm}$ wide $\times 9-\mathrm{cm}$ high), with the front wall, rear wall, and ceiling constructed of clear Plexiglas. The floor and side walls consisted of 3-mm stainless steel rods set 1-cm apart. In Experiment 7, fear conditioning in P30 rats occurred in an identical but larger set of chambers $(20-\mathrm{cm}$ long $\times 12$-cm wide $\times 12$ - $\mathrm{cm}$ high, with the grids spaced $13-\mathrm{mm}$ apart). Underneath the grid floor was a tray of bedding that was cleaned after each training session. A low, constant background noise $(50 \mathrm{~dB})$ was produced by ventilation fans and the sole source of illumination in these chambers was red light-emitting diodes (LED) located on the cabinet wall.

\section{Reacquisition}

In Experiments 1-7, older animals underwent reacquisition in the larger set of training chambers (as described above). In Experiment 7, reacquisition in P17 rats occurred in the smaller chambers (as described above).

\section{Test}

All rats were tested in a set of two identical chambers that were rectangular $(30-\mathrm{cm} \times 30-\mathrm{cm}$ wide $\times 23-\mathrm{cm}$ high $)$ and wholly constructed of Plexiglas. The two side walls consisted of vertical black-and-white stripes (each 5 -cm wide). A low, constant background noise was produced by ventilation fans. White and red LEDs provided illumination in these chambers, except for Experiments 6 and 7 where only the red LEDs provided background illumination in the test chambers.

\section{Drugs}

In all experiments (except Experiment 2), rats were injected subcutaneously in the nape of the neck with either MK-801 (Tocris Bio-science) or saline. In Experiment 1, animals were injected 10-min prior to conditioning, while in Experiments 3-7 animals were injected 10-min prior to reacquisition. MK-801 was freshly dissolved in $0.9 \%$ sterile saline and administered at a dose of $0.1 \mathrm{mg} / \mathrm{kg}$ body weight, in a volume of either $2 \mathrm{~mL} / \mathrm{kg}$ (Experiment 1 ) or $1 \mathrm{~mL} / \mathrm{kg}$ (Experiments 3-7). Rats in the saline condition were given an equivalent volume of sterile saline solution. The dosage of MK-801 used had previously been shown to be effective at impairing initial acquisition in infant and juvenile rats (Langton et al. 2007).

\section{Scoring}

Fear was measured through freezing, scored by a time-sampling procedure whereby each rat was scored as freezing or not freezing every $3 \mathrm{sec}$. Freezing was defined as the absence of all movements, except those related to breathing (Blanchard and Blanchard 1969). A percentage score was calculated for each animal to indicate the proportion of total observations scored as freezing. A second scorer, blind to the experimental group of each rat, scored a random sample of $30 \%$ of the test data; the inter-rater reliability was very high $(r=0.97)$.

\section{Exclusion criteria}

To ensure that freezing levels were reflecting CS-elicited fear rather than contextual fear, any animals exhibiting more than $60 \%$ baseline levels of freezing were excluded from the analysis; across seven experiments, three out of 316 rats were excluded on this basis. In addition, three rats were also excluded because they were statistical outliers at test (performing more than 4 SDs away from the group mean). Last, five animals were excluded due to experimenter error (i.e., injection problem) or not receiving all the shocks during reacquisition.

\section{Procedures}

Experiment 1

P17 rats were given six CS-US pairings; 10 min prior to training, animals were injected with either MK-801 or saline. Rats were placed into the conditioning chambers and, after a 2-min adaptation period, the conditioned stimulus (white noise) was presented for $10 \mathrm{sec}$ and co-terminated with the unconditioned stimulus (0.6-mA footshock). The noise level in the chamber increased by $8 \mathrm{~dB}$ when the white noise was presented. The intertrial interval (ITI) ranged from $85 \mathrm{sec}$ to $135 \mathrm{sec}$ with a mean of $110 \mathrm{sec}$. The presentations of the CS and US were computer-controlled through software that was custom developed at The University of New South Wales. Animals were removed from the testing chambers and returned to their homecage within $30 \mathrm{sec}$ of the last shock. The next day all rats were tested, which involved placing the animal into the test chambers and, after a 1-min adaptation period, presenting the CS for $2 \mathrm{~min}$.

\section{Experiment 2}

Rats were trained as above and then tested 1, 7, or $14 \mathrm{~d}$ later. Rats were tested in the same manner as described above.

\section{Experiment 3}

Rats were trained on P17 and either received six white noiseshock pairings or were exposed to the context for the same amount of time, without any CSs and USs being presented. Two weeks later, these rats (now $31 \mathrm{~d}$ of age) were placed into the reacquisition chamber and after a 2-min adaptation period given three white-noise shock pairings. The stimuli and ITIs were the same as those used during conditioning in Experiment 1 (except only three training trials were given). Ten minutes prior to reacquisition, rats 
received an injection of either MK-801 or saline. The next day, all rats were tested for learned fear, as in the previous experiments.

\section{Experiment 4}

Rats were trained on P17 in a two-phase procedure. In phase one, rats in the paired condition were trained in an identical manner as in Experiment 1. Rats in the unpaired condition were given six footshocks (ITI was $60 \mathrm{sec}$ ) and then removed from the context. Phase two occurred $1 \mathrm{~h}$ later and rats, in both conditions, were placed back into the conditioning context; rats in the paired condition were merely exposed to the context while rats in the unpaired condition received six noise presentations (ITI was $60 \mathrm{sec}$ ). Two weeks later, on P31, all rats were given three white noiseshock pairings. Prior to reacquisition, rats were injected with either MK-801 or saline. All rats were tested the next day for CS-elicited fear.

\section{Experiment 5}

Conditioning, reacquisition, and test procedures were all identical to those in Experiment 3, except the retention interval was $49 \mathrm{~d}$ instead of $14 \mathrm{~d}$. Therefore, rats were adults $(\sim$ P 65$)$ at the time of reacquisition. Animals were not handled between P17 and P65 other than making tail markings every 2 wk.

\section{Experiment 6}

P17 animals were conditioned as described in Experiment 1. Two weeks later, rats were injected with either MK-801 or saline and 10 min later underwent reacquisition, during which rats were trained with either the same CS (three white noise-shock pairings) or a novel CS (three light-shock pairings). The light CS was a 10-sec illumination of a white LED that was mounted on the rear wall of the wood cabinet. When the CS came on, the illumination of the cabinet increased from 0 to $0.29 \mathrm{~cd} / \mathrm{m}^{2}$. The next day, animals were tested for their fear to the CS used at reacquisition (using the same procedures as in the previous experiments).

\section{Experiment 7}

On day 1, P17 and P30 rats were trained with either six or three white noise-shock pairings, respectively; a pilot study had shown that these parameters produce similar levels of CS-elicited freezing the next day at the two ages. The next day, animals were injected with either MK-801 or saline and $10 \mathrm{~min}$ later received three light-shock presentations. On day 3 , all animals were tested for their fear to the light as in Experiment 6.

\section{Acknowledgments}

This work was supported by grants from the Australian Research Council (DP0985554 and DP120104925) to R.R.

\section{References}

Anderson MJ, Riccio DC. 2005. Ontogenetic forgetting of stimulus attributes. Learn Behav 40: 444-453.

Archobold GEB, Bouton ME, Nader K. 2010. Evidence for the persistence of contextual fear memories following immediate extinction. Eur J Neurosci 31: 1303-1311.

Bannerman DM, Good MA, Butcher SP, Ramsay M, Morris RG. 1995. Distinct components of spatial learning revealed by prior training and NMDA receptor blockade. Nature 378: 182-186.

Bauer EP, Schafe GE, JeDoux JE. 2002. NMDA receptors and L-type voltage-gated calcium channels contribute to long-term potentiation and different components of fear memory formation in the lateral amygdala. J Neurosci 22: 5239-5249.

Blanchard RJ, Blanchard DC. 1969. Crouching as an index of fear. J Comp Physiol Psych 67: 370-375.

Bouton ME. 1993. Context, time, and memory retrieval in the interference paradigms of Pavlovian learning. Psychol Bull 114: 80-99.

Butelman ER. 1989. A novel NMDA antagonist, MK-801, impairs performance in a hippocampal-dependent spatial learning task. Pharmacol Biochem Behav 34: 13-16.
Campbell BA, Campbell EH. 1962. Retention and extinction of learned fear in infant and adult rats. J Comp Physiol Psych 55: 1-8.

Campbell BA, Jaynes J. 1966. Reinstatement. Psychol Rev 73: 478-480.

Campbell BA, Spear NE. 1972. Ontogeny of memory. Psychol Rev 79: $215-236$.

Chan WYM, McNally GP. 2009. Conditioned stimulus familiarity determines effects of MK-801 on fear extinction. Behav Neurosci 123: 303-314.

Clem RL, Barth A. 2006. Pathway-specific trafficking of native AMPARs by in vivo experience. Neuron 49: 663-670.

Clem RL, Celikel T, Barth A. 2008. Ongoing in vivo experience triggers synaptic metaplasticity in the neocortex. Science 319: 101-104.

Davis M. 1992. The role of the amygdala in fear and anxiety. Annu Rev Neurosci 15: 353-375.

Davis JM, Rovee-Collier CK. 1983. Alleviated forgetting of a learned contingency in 8-week-old infants. Dev Psychol 19: 353-365.

de Lima MM, Laranja DC, Bromberg E, Roesler R, Schroder N. 2005. Pre- or post-training administration of the NMDA receptor blocker MK-801 impairs object recognition memory in rats. Behav Brain Res 156: $139-143$.

Fanselow MS, Kim JJ. 1994. Acquisition of contextual Pavlovian fear conditioning is blocked by application of an NMDA receptor antagonist D,L-2-amino-5-phosphonovaleric acid to the basolateral amygdala. Behav Neurosci 108: 210-212.

Gale GD, Anagnostaras SG, Godsil BP, Mitchell S, Nozawa T, Sage JR, Wiltgen B, Fanselow MS. 2004. Role of the basolateral amygdala in the storage of fear memories across the adult lifetime of rats. J Neurosci 24: 3810-3815.

Graham BM, Richardson R. 2011. Fibroblast growth factor-2 alters the nature of extinction. Learn Mem 18: $80-84$.

Hardt O, Wang S, Nader K. 2009. Storage or retrieval deficit: The yin and yang of amnesia. Learn Mem 16: 224-230.

Haroutunian V, Riccio RC. 1977. Effect of arousal conditions during reinstatement treatment upon learned fear in young rats. Dev Psychobiol 10: $25-32$.

Kandel ER. 2001. The molecular biology of memory storage: A dialogue between genes and synapses. Science 294: 1030-1038.

Kim JH, McNally GP, Richardson R. 2006. Recovery of fear memories in rats: Role of the $\gamma$-amino butyric acid (GABA) in infantile amnesia. Behav Neurosci 120: $40-48$.

Kim JH, Li S, Hamlin AS, McNally GP, Richardson R. 2012. Phosphorylation of mitogen-activated protein kinase in the medial prefrontal cortex and the amygdala following memory retrieval or forgetting in developing rats. Neurobiol Learn Mem 97: 59-68.

Langton JM, Richardson R. 2008. D-Cycloserine facilitates extinction the first time but not the second time: An examination of the role of NMDA across the course of repeated extinction sessions. Neuropsychopharmacology 33: 3096-3102.

Langton JM, Richardson R. 2010. The temporal specificity of the switch from NMDAr-dependent extinction to NMDAr-independent re-extinction. Behav Brain Res 208: 646-649.

Langton J, Kim JH, Nicholas J, Richardson R. 2007. The effect of the NMDA receptor antagonist MK-801 on the acquisition and extinction of learned fear in the developing rat. Learn Mem 14: 665-668.

Laurent V, Westbrook RF. 2009. Infusion of the NMDA receptor antagonist, DL-APV, into the basolateral amygdala disrupts learning to fear a novel and a familiar context as well as relearning to fear an extinguished context. Learn Mem 16: 96-105.

LeDoux JE. 2000. Emotion circuits in the brain. Annu Rev Neurosci 23: $155-184$.

Lee H, Kim JJ. 1998. Amygdalar NMDA receptors are critical for new fear learning in previously fear-conditioned rats. J Neurosci 18: $8444-8454$.

Maren S, Fanselow MS. 1995. Synaptic plasticity in the basolateral amygdala induced by hippocampal formation stimulation in vivo. J Neurosci 15: 7548-7564.

Miserendino MJ, Sananes CB, Melia KR, Davis M. 1990. Blocking of acquisition but not expression of conditioned fear-potentiated startle by NMDA antagonists in the amygdala. Nature 345: 716-718.

Morris RG. 1989. Synaptic plasticity and learning: Selective impairment of learning rats and blockade of long-term potentiation in vivo by the $\mathrm{N}$-methyl-D-aspartate receptor antagonist AP5. J Neurosci 9: 3040-3057.

National Health Medical Research Council. 2004. The Australian code of practice for the care and use of animals for scientific purposes, 7th ed. Australian Government Publishing Service, Canberra, Australia.

Roberts M, Shapiro M. 2002. NMDA receptor antagonists impair memory for nonspatial, socially transmitted food preference. Behav Neurosci 116: $1059-1069$

Rodrigues SM, Schafe GE, LeDoux JE. 2001. Intra-amygdala blockade of the NR2B subunit of the NMDA receptor disrupts the acquisition but not the expression of fear conditioning. J Neurosci 21: 6889-6896. 
Roesler R, Vianna MRM, Sant' Anna MK, Kuyven CR, Kruel AV, Quevedo J, Ferreira MBC. 1998. Intrahippocampal infusion of the NMDA receptor antagonist AP5 impairs retention of an inhibitory avoidance task: Protection from impairment by retraining or preexposure to the task apparatus. Neurobiol Learn Mem 69: 87-91.

Roesler R, Vianna MRM, de-Paris F, Rodrigues C, Sant' Anna MK, Quevedo J, Ferreira MBC. 2000. NMDA receptor antagonism in the basolateral amygdala blocks enhancement of inhibitory avoidance learning in previously trained rats. Behav Brain Res 112: 99-105.

Sanchez MM, Ladd CO, Plotsky PM. 2001. Early adverse experience as a developmental risk factor for later psychopathology: Evidence from rodent and primate models. Dev Psychopathol 13: 419-449.

Sanders MJ, Fanselow MS. 2003. Pre-training prevents context fear conditioning deficits produced by hippocampal NMDA receptor blockage. Neurobiol Learn Mem 80: 123-129.

Saucier D, Cain DP. 1995. Spatial learning without NMDA receptor-dependent long-term potentiation. Nature 378: 186-198.

Sevelinges Y, Moriceau S, Holman P, Miner C, Muzny R, Gervais R, Mouly A Sullivan RM. 2007. Enduring effects of infant memories: Infant odor-shock conditioning attenuates amygdala activity and adult fear conditioning. Biol Psychiatry 62: 1070-1079.

Sevelinges Y, Sullivan RM, Messaoudi B, Mouly A. 2008. Neonatal odor-shock conditioning alters the neural network involved in odor fear learning at adulthood. Learn Mem 15: 649-656.
Spear NE, Parsons PJ. 1976. Analysis of a reactivation treatment: Ontogenetic determinants of alleviated forgetting. In Processes in animal memory (ed. DL Medin, WA Roberts, RT Davis), pp. 135-165. Lawrence Erlbaum Associates, Hillsdale, New Jersey.

Takatsuki K, Kawahara S, Takehara K, Kishimoto Y, Kirino Y. 2001. Effects of the noncompetitive NMDA receptor antagonist MK-801 on classical eyeblink conditioning in mice. Neuropharmacology 41: 618-628.

Tang HH, McNally GP, Richardson R. 2007. The effects of FG7142 on two types of forgetting in 18-day-old rats. Behav Neurosci 121: $1421-1425$.

Tayler KK, Lowry E, Tanaka K, Levy B, Reijmers L, Mayford M, Wiltgen BJ. 2011. Characterization of NMDAr-independent learning in the hippocampus. Front Behav Neurosci 5: 1-12.

Wiltgen BJ, Royle GA, Gray EE, Abdipranoto A, Thangthaeng N, Jacobs N, Saab F, Tonegawa S, Heinemann SF, O'Dell TJ, et al. 2010. A role for calcium-permeable AMPA receptors in synaptic plasticity and learning. PLOS ONE 5: 1-18.

Wiltgen BJ, Wood AN, Levy B. 2011. The cellular mechanisms of memory are modified by experience. Learn Mem 18: 747-750.

Received November 6, 2012; accepted in revised form January 7, 2013. 


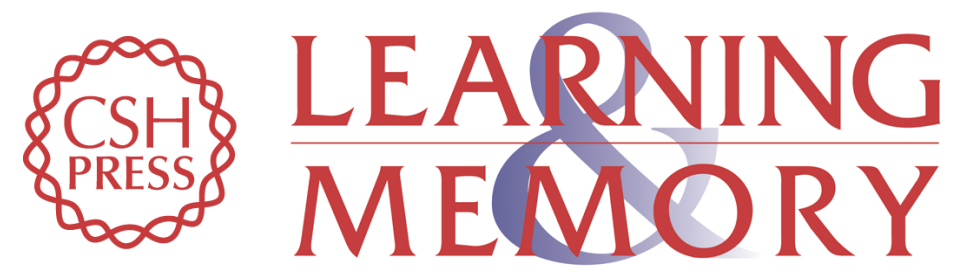

\section{Traces of memory: Reacquisition of fear following forgetting is NMDAr-independent}

Stella Li and Rick Richardson

Learn. Mem. 2013, 20:

Access the most recent version at doi:10.1101/Im.029504.112

References This article cites 47 articles, 14 of which can be accessed free at: http://learnmem.cshlp.org/content/20/4/174.full.htmI\#ref-list-1

License

Email Alerting Receive free email alerts when new articles cite this article - sign up in the box at the Service top right corner of the article or click here. 